\title{
LA MATERIALIDAD DE LA DOMINACIÓN: MAPAS MANUSCRITOS, FUERTES Y REDUCCIONES INDÍGENAS EN LA QUEBRADA DE ESCOIPE (SIGLOS XV-XVIII), VALLE DE LERMA, SALTA, ARGENTINA
}

\author{
THE MATERIALITY OF DOMINATION: MANUSCRIPT MAPS, FORTS \\ AND INDIGENOUS REDUCTIONS IN QUEBRADA DE ESCOIPE \\ (XV-XVIII CENTURIES),VALLE DE LERMA, SALTA, ARGENTINA
}

\author{
Pablo Mignone*
}

\begin{abstract}
En este trabajo se analiza la conformación de un paisaje de dominación mediante la georreferenciación de mapas manuscritos y el traslado de la espacialidad colonial hispanocriolla desde el papel al terreno. La zona estudiada fue conocida como la "boca de la Quebrada del río Escoipe", en el centro-oeste del valle de Lerma, provincia de Salta (Argentina); zona repartida desde fines del siglo XVI en mercedes de tierras a los primeros conquistadores españoles y temprano lugar de asiento de encomiendas de indios. La reconstrucción espacial nos muestra el avance del poder colonial en tierras indígenas y el confinamiento progresivo de los pueblos encomendados y reducidos hacia las márgenes montuosas de "los llanos de Salta" en espacios poco propicios para su reproducción biológica y social, en una relación inversamente proporcional a la valorización económica de las tierras. En este contexto los mapas manuscritos se nos presentan a la vez como la legitimación y el instrumento por el que queda inscripto el despojo sufrido por los colectivos indígenas pulares y calchaquíes frente a sus encomenderos y vecinos hispanocriollos.
\end{abstract}

Palabras claves: SIG histórico, desnaturalización, poder colonial.

In this work, is analyzed the conformation of a landscape of domination by georeferencing manuscript maps and the transference of the Spanish colonial spatiality from paper to the space. The studied area was known as the "mouth of the Quebrada del Rio Escoipe", in the center-west of the Lerma Valley, Salta province (Argentina); an area distributed since the end of the sixteenth century in land grants ("mercedes") to the first Spanish conquerors and an early place of seat of indigenous "encomiendas". The spatial reconstruction shows us the advance of the colonial power over indigenous lands and the progressive confinement of the entrusted and reduced towns towards the mountainous margins of "the plains of Salta" in spaces that were hardly suited to their biological and social reproduction, in an inversely proportional relationship to the economic valuation of the lands. In this context, the manuscript maps are presented to us both as the legitimation and as the instrument by which the dispossession suffered by the Pular and Calchaquí indigenous groups in front of their Spanish-Creole encomenderos and neighbors is registered.

Key words: Historical GIS, denaturalization, colonial power.

\section{Introducción}

En el artículo que se presenta investigaremos acerca del origen y consolidación de un espacio de dominación colonial español en el sector centro occidental del valle de Lerma, provincia de Salta, Argentina. En este lugar se creó una de las primeras mercedes de tierras y encomiendas otorgadas a los conquistadores españoles y fueron asentados indígenas desnaturalizados del valle contiguo, el valle Calchaquí.

La zona posee un marcado conato estratégico por estar situada a la vera de uno de los grandes sistemas hidrográficos que conectan el valle de Lerma con el valle Calchaquí y las tierras altas de la puna, la quebrada del río Escoipe, perteneciente este curso a la Alta Cuenca del río Juramento al igual que el río Calchaquí. Ambos de gran importancia para la historia prehispánica, ya que favorecidas por su riego casi permanente florecieron las sociedades indígenas más numerosas del noroeste argentino.

La conquista y posterior colonización española buscó aprovechar esta concentración de población como mano de obra para el trabajo en las minas que,

\footnotetext{
* Instituto de Ciencias Sociales y Humanas (ICSOH), Universidad Nacional de Salta - CONICET. Salta, Argentina. Correo electrónico: pmignone@ hotmail.com
} 
se creía, existían al amparo de la reticencia de los indígenas por revelar su ubicación. Los intentos por reducir al sistema de encomienda y al trabajo minero a estos grupos no se hicieron sin antes un proceso bélico intermitente de casi 150 años de duración conocido como "las rebeliones calchaquíes".

Al finalizar este proceso, promediando el segundo tercio del siglo XVIII, el espacio de dominación colonial tendrá su apariencia casi definitiva, mediante la desnaturalización de los grupos indígenas rebeldes a distintos puntos de la entonces gobernación del Tucumán. En este contexto los "llanos de Salta" también conocidos como "la boca de la Quebrada de Escoipe", es el resultado de las encomiendas del siglo XVI, de las desnaturalizaciones y traslados posteriores a las rebeliones calchaquíes de 1630-43 y de 1659-66 y de los otorgamientos, divisiones y agregaciones de encomiendas a lo largo de todo el siglo XVII (Castro Olañeta 2018).

Como objetivo particular se busca reconstruir estos paisajes de dominación a partir de la georreferenciación de mapas manuscritos mediante un Sistema de Información Geográfica (SIG) que acompañan un largo litigio por tierras entablado entre los grupos pulares desnaturalizados y sus encomenderos ${ }^{1}$.

Para entender la formación del espacio colonial usaremos esos documentos junto con mercedes de tierras y cédulas de encomienda, algunos de ellos publicados y otros que se encuentran en los fondos del Archivo General de la Nación (AGN en adelante) y en el Archivo General de Indias (AGI en adelante), además de técnicas arqueológicas de prospección y excavación.

Los resultados indican que la morfología de los espacios de dominación fue cambiando según la época y los intereses de los grupos hispanocriollos de poder, resultando en la completa desposesión de los grupos indígenas.

\section{EI SIG histórico y los mapas manuscritos}

La reconstrucción de los paisajes de dominación colonial será encuadrada dentro de los planteos teóricos y metodológicos del SIG histórico (historical GIS en inglés), los que buscan aplicar la tecnología del SIG para responder a preguntas históricas a base de cuestiones geográficas y espaciales (Knowles 2005; Siebert 2000; Bodenhamer et al. 2010).

En el marco de los SIG, la georreferenciación es el proceso por el que se seleccionan puntos de control de un mapa histórico y se los alinea con modernos sistemas geodésicos, ya sea asignándole manualmente coordenadas geográficas a cada punto o relacionando cada punto del mapa original con el mismo punto en un mapa moderno, digital y preciso (Rumsey y Williams 2002).

Colocados los puntos de control en su lugar, se aplican algoritmos matemáticos para que el mapa original se ajuste a la proyección elegida de una manera conocida como rubber sheeting, mediante esto, la imagen se estira o encoje como una fina hoja de goma para que encaje a un sistema de coordenadas nuevo (Rumsey y Williams 2002), debido a que o bien se desconoce la proyección cartográfica original, o su sistema geodésico de referencia es histórico y se encuentra en desuso (Dávila y Camacho 2012).

La falta de adecuación a cualquier sistema geodésico histórico puede relacionarse también al hecho de que la cartografía se inscribe en el seno mismo de relaciones de poder, siendo la representación gráfica una forma de visualización de lo social antes que de lo topográfico (Harley 1989).

De la misma forma que el arte, el mapa se convierte en el mecanismo para definir relaciones, sostener reglas o fortalecer valores sociales, no solo mediante el discurso o de formas más codificadas o violentas de ejercer el poder, sino también por medio de los elementos pictóricos que lo conforman: tamaños de los símbolos, grosor de las líneas, el alto de las letras, las técnicas de sombreado, la adición de color, etcétera (Harley 1989).

En la cartografía española en América la representación espacial fue producto de la necesidad de tener un panorama adecuado de los elementos geográficos y humanos a gobernar. Los cartógrafos y cosmógrafos, en este contexto, fueron por lo general funcionarios reales, por lo que su registro de las cosas "naturales y morales" del Nuevo Mundo, era principalmente la manera de comunicar a las autoridades la magnitud y características de sus dominios (Buisseret 2007).

Como sostiene Quiroga (2017) para el caso del Tucumán colonial del siglo XVII, la cartografía enmascaró la compleja trama de relaciones de alianza formada por otros distintos colectivos étnicos contra la conquista europea y fue un recurso más dentro de las vastas estrategias materiales desplegadas por el poder español para construir un paisaje de dominación colonial. 


\section{La construcción del paisaje colonial}

Los "llanos de Salta" es el nombre con el que se conoció una pequeña zona del valle de Lerma ubicada a $30 \mathrm{~km}$ al sudoeste de la ciudad de Salta, en la desembocadura del río Escoipe, naciente de la quebrada homónima (Figura 1). En este corredor natural que conecta el valle de Lerma con el valle Calchaquí se han registrado tramos de caminos inkaicos (Vitry 2004) cuya infraestructura fue aprovechada parcialmente por el poder colonial mayor para asegurar las comunicaciones entre la Provincia de Diaguitas, Lules y Juríes con Potosí (Quintián 2008; Mignone 2020).

Dentro de este proyecto de ocupación efectiva del territorio se suceden los intentos de consolidación del poder en los valles calchaquíes, con suerte dispar. Con la orden del virrey Toledo de establecer una población en el valle de Salta o en
Calchaquí para asegurar el comercio con el centro del virreinato del Perú mediante una red de caminos, el gobernador Gonzalo de Abreu y Figueroa funda en 1577 San Clemente de la Nueva Sevilla en el valle Calchaquí (en el sitio de Samalamao, al sur de San Carlos, próximo a Cafayate, Salta, Giudicelli 2013), en una ubicación ventajosa por contar con sementeras, dominio visual del valle y poblaciones de indígenas para incorporar al sistema laboral español (Levillier 1920: 59).

Una vez realizada la fundación, y a pesar de contar con "... muchos cavallos armas cotas e arcabuzes comida e bastimientos necesarios e yndios de servicio e otros peltrechos de guerra en muy y mucha cantidad..." (Levillier 1920: 149), Abreu encomienda a 40 de sus mejores hombres dirigirse a Charcas en busca de bastimentos, momento aprovechado por los calchaquíes para destruir la efímera ciudad.

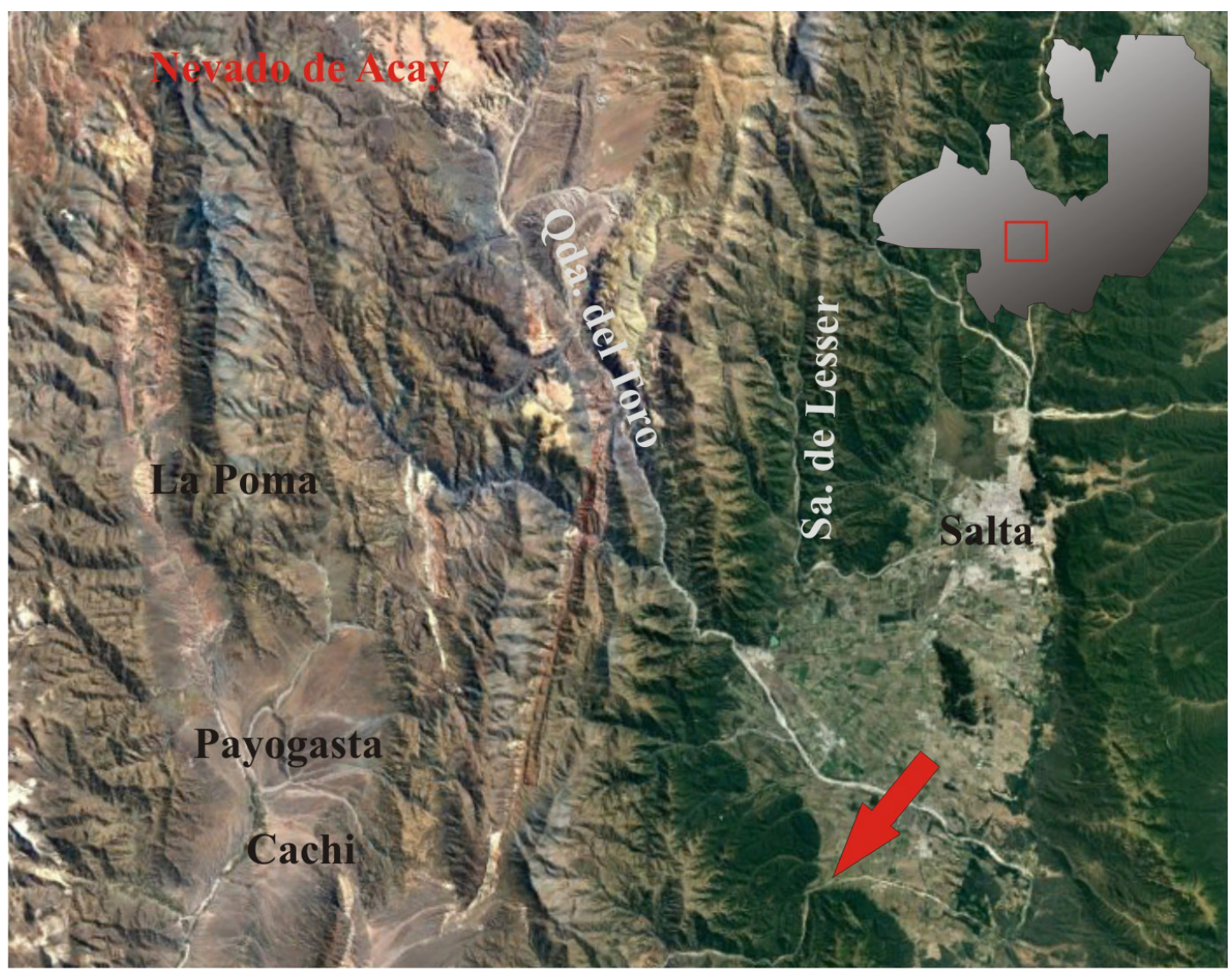

Figura 1. Ubicación de la boca de la quebrada de Escoipe y lugares cercanos. 
Decide luego mudar la población a la desembocadura de la quebrada del río Escoipe en el valle de Salta. Estando en esta segunda San Clemente tuvo que partir a Santiago del Estero a ocuparse de nuevos asuntos. Al poco tiempo un ataque indígena llevó a despoblar la ciudad y a replegar las fuerzas españolas hasta San Miguel. Ante la noticia, el gobernador decidió reedificarla. No tardó mucho en tener que defender nuevamente su fundación ante otra serie de ataques (Levillier 1920).

Repelidos los mismos, se dispuso a poner en condiciones de ser poblada y sostenida la ciudad y alrededores con sementeras. Terminada la obra un grupo de sus mejores soldados, armados, huyó al Perú dejando desamparado al gobernador y a sus pocos defensores. Una confederación indígena golpeó la fundación obligando a Abreu a huir nuevamente a San Miguel (Levillier 1920).

Una tercera fundación de San Clemente en la actual localidad de Campo Santo, en el valle de Siancas, a más de $100 \mathrm{~km}$ al este del asentamiento anterior y próxima al camino real hacia Charcas, tampoco prosperó (Cornejo 1934). La repetida suerte de estas tres ciudades fue uno de los argumentos del gobernador entrante, Lerma, para formarle juicio de residencia a Abreu acusándolo, entre otros 56 cargos, de incumplir el pleito homenaje entre este último y el virrey Toledo por el que estaba obligado a formar población estable en Calchaquí o en el valle de Lerma (Levillier 1920: 23).

\section{La fundación de Salta. Primeras mercedes y encomiendas}

Tras la muerte de Gonzalo de Abreu por los suplicios aplicados en su detención y traslado desde Santiago a San Miguel, Lerma intenta un nuevo poblamiento del valle de Salta al que se dirige con un gran contingente de soldados fuertemente armados y pertrechados (detalles en Levillier 1920: 96-121). Se realiza así la fundación de la ciudad de Lerma en el valle de Salta; una ubicación estratégica debido a que permitía tener un jalón para ocupar el valle Calchaquí (Quiroga 2017) y explotar al fin las tan mentadas minas "en los términos de los pulares", así como había sido el objetivo de Abreu forzosamente pospuesto (Levillier 1920).

Si bien el eje fundacional se había mudado 40 $\mathrm{km}$ hacia el noreste con la creación de la ciudad de Salta, el asiento de la segunda San Clemente en la boca de la quebrada de Escoipe siguió teniendo cierta gravitación y fue el pivote alrededor del cual se erigieron las primeras encomiendas y mercedes del valle.

Uno de los participantes de la hueste fundadora, Bartolomé Valero, recibió, entre otras dignidades que incluían tierras y cargos gubernamentales, la encomienda de indios Pulares, Escoipes y Guachipas, ubicada en el pueblo de Escoipe, a $20 \mathrm{~km}$ al oeste de San Clemente de Abreu. Encomienda de la que hará dejación en 1586 en favor de Román Valero, su sobrino, y de Pedro Valero, su hijo natural (Quiroga et al. 2018), pero que volverá a su poder a la muerte de ambos (Castro Olañeta 2018).

Dicha encomienda a su vez será partida, manteniendo una de ellas el nombre "Escoipes, Pulares y Guachipas", en el pueblo de Escoipe (en la quebrada homónima), mientras que el otro repartimiento, llamado simplemente "Pulares", será asentado en los llanos del valle de Lerma, en la desembocadura de la quebrada de Escoipe, en los alrededores de la fundación de Abreu. Por una cuestión de espacio, remitimos al lector a Castro Olañeta (2018) para ver la conformación y traspaso de estas encomiendas con detalle.

Teniendo a San Clemente como referencia, el "cacique de repartimiento de pulares", Calibay, solicitó una merced de tierras al teniente de gobernador y justicia mayor, Valero, de una "legua de ancho por cualquier parte" hasta la "poblazon" de Abreu (Giudicelli 2013). En 1586 también Valero otorgó al tesorero Diego de Robles una merced de tierras colindantes con el fuerte de Abreu por el este. En este contexto la fundación de Abreu pasó de tener carácter defensivo a ser solamente un mojón en el reparto de tierras en el lugar.

La renuencia de los indígenas a acudir al servicio de la ciudad de Salta y al valle de Lerma en general, sumado al hecho de que el norte del valle Calchaquí "estaba alzado" (Levillier 1920), hacían bastante poco atractivo el asentamiento en las inmediaciones del fuerte de Abreu, expuesto por su ubicación al ingreso de los indígenas rebeldes del valle contiguo. Recién a partir de la pacificación de la frontera calchaquí y del posicionamiento del valle de Lerma como lugar de paso hacia Potosí y al Perú a mediados del siglo XVII, se despierta el interés por adquirir tierras (Mata 2005).

Las ubicadas al este del pucará de Abreu pertenecientes a Diego de Robles, ya mencionadas, serán adquiridas por Bartolomé Valero en remate público en 1604: “...media legua linderos al norte con el 
pucará de abreu, ambos lados del río, para estancia de bacas, yeguas y ovejas. Con poco adelante doce fanegadas de tierra para sembrar maíz y otras dos fanegadas para sembrar trigo..." (AGN, Tribunales, Legajo 45, Expte.2, Sala 9, 91r.).

\section{Los alzamientos indígenas y las reducciones en el valle de Lerma}

Dichas tierras fueron luego puestas como dote para el matrimonio entre su hija Ana y Juan de Abreu, encomendero del valle Calchaquí e hijo natural del gobernador Gonzalo de Abreu y Figueroa. Tras la muerte de Ana Valero, su esposo otorgó nuevamente como dote esta estancia de ganados mayores y menores para el matrimonio entre su medio hermana, Isabel de Figueroa, y Bartolomé Fernández (AGN, Tribunales, Legajo 45, Expte.2, Sala 9, 73r.).

Si bien la creciente demanda de ganado en pie por parte de las minas de Potosí y las tabladas de Cusco hizo de esta zona un promisorio polo económico, a la muerte de Fernández su viuda abandonó el interés por estas tierras y las trocó al rector del colegio de la Compañía de Jesús, padre Pedro Herrera, por otras que la Orden poseía en la ciudad de Salta (AGN, Tribunales, Legajo 45, Expte.2, Sala 9, 76r. y v.), manteniendo, no obstante, la encomienda de indios pulares hasta su muerte.

En 1629, luego de su muerte, la encomienda de Escoipes, Guachipas y Pulares fue otorgada a Miguel de Elizondo por dos vidas (Archivo General de Indias, CHARCAS, 101, N.51), mientras que la de Pulares del valle de Lerma, que poseía Román Valero pero que tras su muerte recuperó Bartolomé Valero y pasa a su hija, fue otorgada a Álvaro Vélez de Alcocer (Archivo General de Indias, CHARCAS, 102, N.22).

La paz relativa de la que gozaba Salta cambió del todo al finalizar el primer tercio del siglo XVII. En 1630 las noticias acerca de las riquezas minerales ocultas en el valle Calchaquí (Quintián 2008) y el intento de fundar un nuevo pueblo de españoles en él, motivaron la segunda rebelión indígena o Alzamiento General (1632-1643), aliándose en 1631 numerosos pueblos del sur del valle (Lorandi 1988).

El teniente de gobernador Felipe de Albornoz realizó un primer intento de pacificación desde Salta con el auxilio de los pulares del norte del valle Calchaquí. Como respuesta los calchaquíes atacaron el pueblo de Atapsi matando ...más de sesenta indios del pueblo de los Chiquanas y otros muchos del pueblo de los Coypes por haber en aquella ocasión ayudado a los españoles... (Carta de Albornoz a S. M. Santiago del Estero, 1/III/633, en Larrouy 1927: 78).

El ataque forzó la emigración de 800 indígenas pulares y sus familias primero en el "término del valle de Salta", en Pampa Grande, Guachipas, y luego al valle de Salta, asentándose en la boca de la Quebrada, junto con los pueblos ya encomendados a Valero y familia desde 1582 (Castro Olañeta 2018).

Para proteger a Salta y a sus aliados pulares de nuevas incursiones calchaquíes, Albornoz creó el fuerte de San Bernardo (Larrouy 1927: 92) a seis leguas al sur de esta ciudad y dos a leguas de la boca de la quebrada de Escoipe (Piossek Prebisch 1983), desplazándose el eje defensivo de esta forma desde el sur hasta el centro del valle de Lerma.

Muchos grupos que habitaban el sector medio del valle Calchaquí y que participaron activamente de la rebelión, como los indios de Taquigasta, Sicha y Cafayate, fueron reducidos junto con los pulares en las cercanías de la fundación de Abreu y de la Chicoana actual; algunos más quedaron en su natural bajo el control de sus encomenderos, como los indígenas de Hualfingasta, Chuchagasta, Animaná, Bombolán, Anguingasta, Pompoma, Ampascachi, Casmichango y Tolombón, entre otros (Castro Olañeta 2007).

La relativa paz que dejó el feroz apaciguamiento de la segunda rebelión calchaquí duró poco. Veinte años más tarde un aventurero andaluz, Pedro Chamijo o Bohórquez, encabezó el tercer alzamiento indígena (1656 a 1666) al frente de algunos grupos del valle Calchaquí (principalmente sichas y cafayates) y pulares (cachis, chicoanas y payogastas) (Lorandi, 2005).

El gobernador Mercado y Villacorta fue el responsable de apagar los focos de resistencia mediante un castigo ejemplar con el objeto, entre distintos fines económicos, de limpiar su imagen ante las inauditas concesiones que le había otorgado a Bohórquez, entre ellas, la de usar título de Inca y vestir los ornamentos de los soberanos cuzqueños (Giudicelli 2018).

Realizó entonces la desnaturalización de todos los pobladores del valle Calchaquí y repartió a los vencidos entre los soldados de las huestes españolas. Los pulares aliados a Bohórquez, no obstante, lograron pactar su rendición en términos favorables obteniendo una amnistía (Castro Olañeta 2018). 
En 1662 fueron reducidos en la boca de la quebrada de Escoipe junto con el resto de las encomiendas de pulares ya existentes en un espacio de media legua cuadrada que tuvieron que comprar a sus encomenderos con la suma de 600 pesos pagados en servicios personales. En otra media legua fueron ubicados los rebeldes Chicoanas, Cafayates y Atapsis que pagaron igual suma y de la misma manera (AGN Tribunales, Legajo 45, Expte. 2, Sala 9 35.7.6).

Una práctica que no fue interrumpida por la guerra fue la del envío de los indígenas por parte de sus encomenderos a distintos puntos de la gobernación y en muchos casos a destinos fuera de ella, como las tabladas del Cusco y las minas de Potosí. Ya desde 1632 se observa en el padrón del repartimiento de pulares encomendado a Andrés de Frías Sandoval, que los trabajos prestados por los indígenas incluían el traslado a las minas de Potosí llevando ganado o bienes de la tierra, el servicio en las estancias cercanas de vecinos de la zona, el concierto con vecinos de Salta y Jujuy, el aprovisionamiento de la comunidad ("a comprar maíz"), o bien, el trabajo en "las minas" (AGI, CHARCAS,101, N.54, "Confirmación de encomienda de pulares").

En 1671 el gobernador Ángelo de Peredo reconoció en los pueblos y reducciones indígenas de Salta una notoria disminución que respondía a la continuidad de esta práctica por parte de los encomenderos. Para dar cuenta de la situación irregular envió al corregidor de las reducciones de Salta, Francisco de Páez, y al justicia mayor, Antonio de Cabrera, los que informaron que de las 18 encomiendas de la jurisdicción de Salta las encomiendas de pulares (encomienda de Payogasta de Luis Arias Velásquez, y Pulares Grande de Diego Vélez de Alcocer, por ejemplo), presentaban un mayor porcentaje de trasladados en comparación a otras de la jurisdicción, llegando a casi $80 \%$ de la población tributaria (González Rodríguez 1982: 54).

Veinte años después de la vista de Francisco de Páez se produjo la visita del oidor de la Audiencia de Charcas, Antonio Martínez Luján de Vargas a todas las encomiendas del Tucumán, la que dejó de manifiesto que si bien a nivel general las encomiendas de pulares eran las que poseían la mayor cantidad de tributarios, evidenciaban, no obstante, una disminución de más del $60 \%$ respecto de 1673 (Quintián 2008).

Por la misma época, el cura propietario de la doctrina de Chicoana informó que los indígenas de los pueblos desnaturalizados por el gobernador Mercado y Villacorta en su doctrina estaban “...disipados y fuera de sus reducciones los indios con sus mugeres e hijos en las estancias y chacras de sus encomenderos, sujetos a servicio personal..." (carta del obispo de Tucumán, en Mata 2005: 61).

Además de los traslados y el servicio personal sufridos por los indígenas, tuvieron que enfrentar la usurpación de sus tierras por parte de sus encomenderos. A pesar de haber comprado las tierras a Álvaro Vélez de Alcocer, 30 años más tarde de su desnaturalización los pueblos de Cachi y Payogasta debieron acudir a la Audiencia de Charcas porque este encomendero aprovechando el paso del tiempo desde la venta había ocupado nuevamente las tierras cedidas expulsando a un pueblero indígena.

Las diversas gestiones atravesadas infructuosamente para recuperar sus tierras constan en expedientes judiciales depositados en el AGN (trabajados por Mata 2005, Quintián 2008 y Castro Olañeta 2018), y cuentan con dos mapas que permiten seguir la espacialidad del pleito. El eje que toman tanto los sucesivos defensores de naturales cuanto los vecinos feudatarios que impugnaron la propiedad de los indios, es siempre la población fundada por Gonzalo de Abreu.

Mientras los indígenas alegaron que las tierras compradas por ellos se extienden hacia el oeste tomando como mojón dicho fuerte y a ambas márgenes del río Chicoana, Álvaro Velez de Alcócer ocupa la margen sur del río, se apropia de un cercado de piedras para guarda de ganado que tenían los indígenas en el lugar, y niega que el arreglo fuese por ambas márgenes, alegando que solamente correspondían las tierras aledañas a dicho fuerte en media legua cuadrada.

Como hemos mencionado en páginas anteriores, al sur del fuerte de Abreu se encontraba una estancia que cambió repetidas veces de mano durante la primera mitad del siglo XVII. Primero perteneció a Bartolomé Valero y fue heredada por su hija Ana Valero, casada con un hijo natural de Gonzalo de Abreu, Juan de Abreu. Este la otorga como parte de la dote de su medio hermana, doña Isabel de Figueroa, que contrae matrimonio con Bartolomé Fernández (quien en 1614 la compra por algunas desinteligencias acerca del origen de la propiedad de las tierras en dote) conociéndose desde entonces y por todo el siglo XVII como "Estancia de Fernández". Al enviudar en 1629, Isabel de 
Figueroa trueca las tierras a la Compañía de Jesús por otras que la orden tenía en la ciudad de Salta.

En dicho lugar, la Compañía erige colegio y perchel. En 1761 los jesuitas también disputaron con los remanentes de Cachi y Payogasta la posesión de las tierras sosteniendo que la cesión hecha por la hermana de Juan de Abreu también les correspondía y que los pueblos de indios se encontraban "yermos y despoblados" (AGN, Tribunales, Legajo 254. Expte. 5. Salta 9 39.4.5, fs. 158 r.).

La expulsión de los jesuitas, lejos de traer sosiego a los pulares, sumó otro episodio más al litigio. El remate público de sus propiedades en el valle de Lerma por orden de la Superior Junta de Temporalidades de Buenos Aires se produjo en 1786; entre las propiedades se encontraba la "Estancia de la Quebrada", la que incluía tierras, casa y perchel y que era servida por las encomiendas de indios pulares de la zona. Su nuevo poseedor, Pedro Arias Velásquez, buscó extender dichas posesiones a todas direcciones, incluyendo las mercedes de tierras entregadas a otros vecinos y las tierras compradas por los indígenas, poniendo además arrendatarios a quienes les cobraba las respectivas rentas.

Se procedió a deslindar las propiedades por medio de un agrimensor, Joaquín Marín, y a personas "prácticas e inteligentes", como Juan José Arias Vidaurri y José Fermín de Zabala, con todos los autos del pleito, una gruesa compresa de 600 folios bajo el brazo, para que levantaran luego de medir y amojonar un paño de pintura o mapa "chinográfico" a presentar a la Junta municipal con el fin de lograr su aprobación (Figura 2). Con el mapa rubricado y aprobado se pasó en 1791 al remate de las tierras en 520 pesos.
El deslinde que acompaña el mapa fue favorable a Pedro Arias, ya que incluyó como parte de la "Estancia de la Quebrada" las tierras indígenas. El segundo mapa fue confeccionado por el protector de naturales, José León de Ojeda, como parte de su denuncia por este despojo.

Desconocemos por el momento el resultado final del proceso judicial y de la suerte del reclamo indígena por las tierras. Sin embargo, algunos aspectos indican que los encomenderos y propietarios buscaron dar por vacas las tierras de la quebrada para que les fueran adjudicadas, práctica corriente en toda la gobernación y muy particularmente en Córdoba del Tucumán para la misma época (Tell 2018).

Que no exista referencia actual de este proceso en la memoria oral de la zona ni se conozca este litigio y la posesión de tierras que los documentos sostienen, es una evidencia contundente a favor del éxito de la usurpación.

\section{Resultados de la georreferenciación}

En términos simbólicos, por la disposición de los hitos en el paisaje, la orientación cardinal y el tipo de figuras usadas como símbolos cartográficos, estos mapas manuscritos muestran reminiscentes medievales a pesar de lo tardío de ambos (Figura 3). Resulta llamativo que en momentos en los que la cartografía se encontraba muy avanzada, se mantenga la expresión figurativa de las construcciones, vistas de costado, al igual la de los aspectos naturales como los cerros, los ríos y los árboles, además de la ausencia de referencias geográficas o geodésicas (o de distancia).
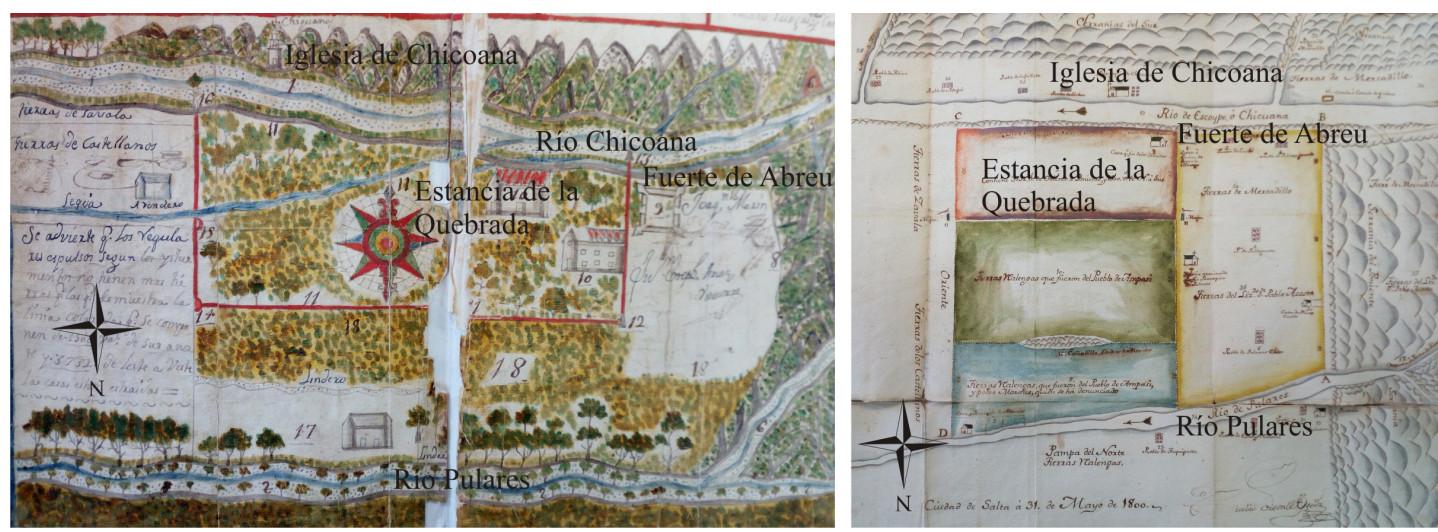

Figura 2. Mapa (recortado) de 1786 (izquierda) y mapa (recortado) de 1800 (derecha) (AGN Tribunales Leg. 45 Expte. 2 Sala 9-35.7.6). 

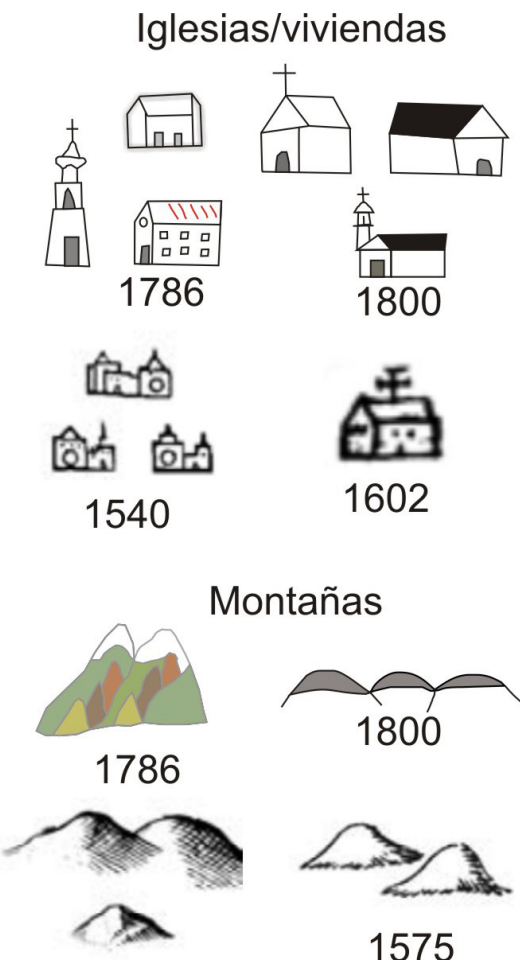

1593
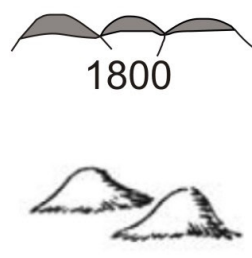

1575
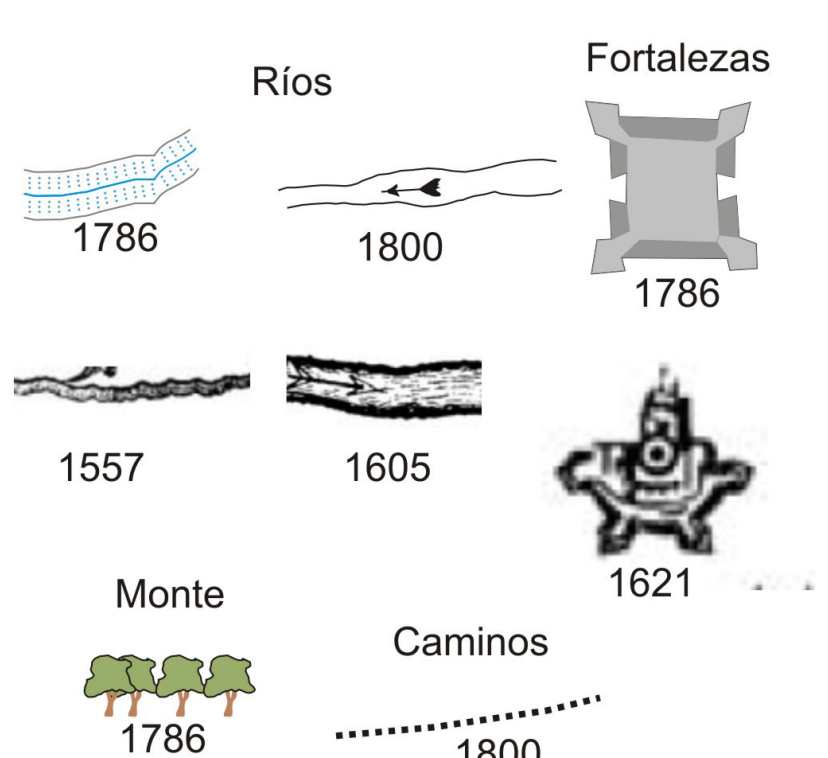

\section{Caminos}
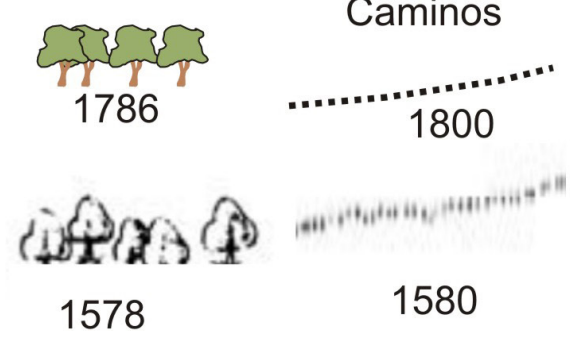

Figura 3. Signos de mapas impresos durante el renacimiento europeo (según Delano Smith 2007) y los dibujados en los mapas del litigio pular (1786 y 1800).

La diferencia entre ambos mapas, al menos a simple vista, radica en que el primero carece del detalle de los pueblos, nombre y ubicación, mientras ahonda más bien en las características geográficas, ubicación de los ríos y arroyos y elementos del paisaje fácilmente identificables (propio del oficio del agrimensor que lo hizo), mientras que el segundo abunda en detalle de los pueblos pero es menos riguroso en la ubicación de hitos paisajísticos.

Como hemos mencionado ya, esto se debe a que ambos fueron creados con fines políticos distintos: el primero de ellos, de 1786, dibujado para deslindar las tierras de los jesuitas expulsos asignadas a su nuevo propietario, Pedro Arias Velásquez, y el segundo, de 1800, confeccionado con el objetivo de rectificar el primero, aduciendo que los pueblos de indios todavía existían y que los deslindes avanzaban sobre las tierras comunales sin respetar las antiguas propiedades comunales.

En la Figura 4 se observan los puntos de control elegidos para georreferenciación, la dirección del error (con flechas rojas), la magnitud del error (simbolizada por la longitud de las flechas) y los valores de rotación, traslación, escala y el error medio en pixeles. Según estos resultados los mapas tienen llamativas semejanzas y algunas diferencias que vale remarcar.

En cuanto a las semejanzas, tienen una diferencia de error medio de 47 pixeles, lo que es una diferencia menor teniendo en cuenta que ambas representaciones gráficas fueron realizadas a mano. Esto nos estaría indicando que el mapa del protector de naturales es, probablemente, una copia del de 1786.

Los valores negativos en la traslación significan que ambos mapas se desplazan hacia la izquierda de los puntos reales en terreno. La rotación negativa en ambos, significa también que la diferencia con el terreno se da en sentido contrario a las agujas del reloj, es decir, que las ubicaciones están desfasadas hacia el este y sur.

En cuanto al sentido del desplazamiento de los puntos de control se observan dos agrupaciones. Los puntos $0,1,2$ y 5 se desplazan hacia la izquierda 


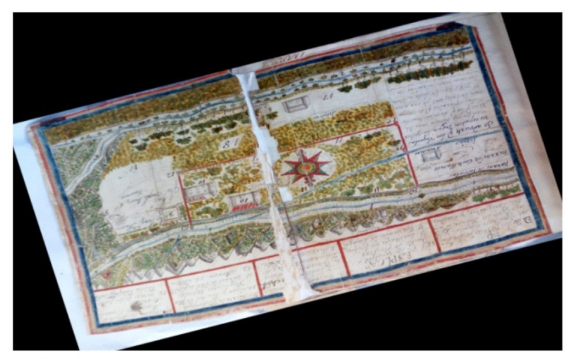

1786

$f^{9}$
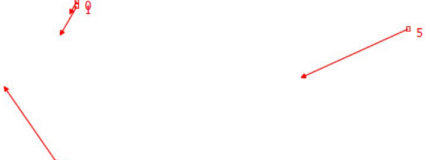
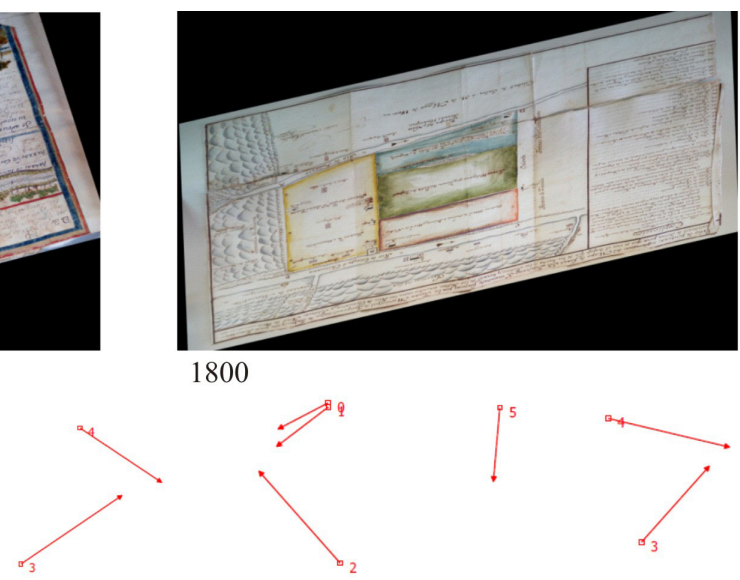

1800
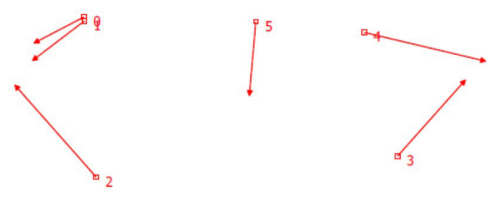

\begin{tabular}{|l|l|l|l|l|l|}
\hline Traslación X & Traslación Z & Escala X & Escala Y & Rotación (grados) & Error medio [píxeles] \\
\hline
\end{tabular} \begin{tabular}{|l|l|l|l|l|l|}
\hline Traslación X & Traslación Z & Escala X & Escala Y & Rotación (grados) & Error medio [píxeles] \\
\hline
\end{tabular} \begin{tabular}{|l|l|l|l|l|l|l}
\hline-65.456 & -25.115 & $3.42925 \mathrm{e}-05$ & $3.42925 \mathrm{e}-05$ & -169.953 \\
\hline
\end{tabular} 482.396

Figura 4. Resultados georreferenciación: valores, magnitudes y dirección de errores. Puntos de control: Iglesia de Chicoana (0), río Chicoana (1), río Escoipe (2), río Escoipe-naciente (3), confluencia ríos Astudillo y Chicoana (4).

(dirección este) mientras que los restantes, 4 y 3 lo hacen hacia la derecha (dirección oeste), como si tuviesen dos ejes de referencia distintos: los primeros tres, agrupados alrededor del pueblo de Chicoana, mientras que los restantes lo hacen en referencia a las sierras occidentales.

Atendiendo a los puntos de referencia 0 y 1 de ambas representaciones (correspondientes a la iglesia de Chicoana y al río Chicoana) vemos que poseen el desplazamiento mínimo según las flechas rojas, lo que nos indicaría que los dos fueron dibujados en los alrededores de esos puntos. Lo anterior nos estaría sugiriendo que el deslinde de 1786 en virtud del remate de las tierras jesuitas, si nos atenemos a su mapa respectivo, se hizo sin la presencia del agrimensor en la propiedad en cuestión. Algo que repitió el protector de naturales al copiar el mapa que buscó corregir.

Existen también diferencias entre ambos. Si se rectifican los mapas sin mantener sus dimensiones y proporciones ("estirándolos"), vemos que el segundo se deforma más que el primero (Figura 4). Es decir, que mientras el de 1786 busca representar grosso modo la realidad espacial de lo representado, el de 1800 lo copia sin intención aparente de ser fiel a la distribución de los hitos del paisaje.

$\mathrm{Al}$ relacionar estos aspectos a la problemática más general del despojo sufrido por los pulares, surgen otros a considerar. En primer lugar, todo el espacio sujeto de litigios involucra la inicial "petición de Calibay" de una legua cuadrada (Giudicelli
2013), la que abarcaba tanto los llamados "llanos de Salta" como las estribaciones de las serranías circundantes.

En segundo lugar, se muestra una superposición de derechos de acceso a la tierra indígena, ya que en 1662 la mitad de ese espacio es vendido a los indígenas desnaturalizados del valle Calchaquí, de los pueblos de Cachi y Payogasta, espacio que, por otro lado, ya estaba ocupado por las encomiendas originales de Valero y sus sucesores, por los grupos huidos del valle calchaquí en la década de 1630 y los vencidos en la misma época una vez finalizado el segundo alzamiento calchaquí.

En tercer lugar, llama la atención que si bien el segundo mapa rectifica los errores del anterior y denuncia los intentos de apropiación de la tierra indígena por parte de los estancieros de la zona (en particular, de Arias Velázquez), el grado de error en su confección es mayor que el primero, como ya se dijo, lo que estaría mostrando que el mapa de 1786, hecho en el terreno y con técnicas topográficas de la época, muestra el verdadero estado de cosas que el mapa de 1800 trata de enmendar.

Vemos entonces que el proceso de despojo denunciado por los caciques de Cachi y Payogasta a fines del siglo XVII, un siglo después era un hecho consumado. En ocasión de la visita de Luján de Vargas a fines del siglo XVII el cacique Chumbicha manifiesta no poseer "...comodidad ninguna así por el corto sitio como por la mala calidad de dichas tierras..." (Castro Olañeta 2018). 
En la Figura 5 se ha intentado una reconstrucción de la espacialidad de la reducción de indios pulares a base de la información documental y la georreferenciación. De la legua cuadrada otorgada a Calibay en 1586 al deslinde de 1786 se evidencia la drástica disminución del hábitat indígena acorde con la creciente valorización de las tierras del valle de Lerma señalada por Mata (2005).

El despojo no fue significativo solo en extensión sino también en calidad. El hábitat de los grupos étnicos que habitaron el norte del valle Calchaquí en los momentos previos a la conquista española pudo haberse extendido hasta el valle de Talina en la actual Bolivia (con una gran diversidad de ambientes y amplias posibilidades de acceso a recursos), según la propuesta de Giudicelli (2011). Sin embargo a fines del siglo XVIII la estrecha franja de tierras que se reconocía como propiedad indígena era descripta como en "...barrancas y cordilleras lleno de monte y es muy poco lo que// se puede aprovechar..." (AGN Tribunales Leg. 45 Expte. 20, Sala 9-35.7.6, fs. 96v.).

Mientras el reconocimiento de las tierras indígenas era reducida a una mínima expresión y movida del llano a los cerros y montes en sentido este-oeste, la estancia de "la Quebrada" perteneciente a los jesuitas y luego adquirida en remate por Arias Velásquez, siguió el camino inverso. Se expandió desde su ubicación original hacia todos lados, avanzando no solamente sobre las posesiones indígenas sino también sobre la de otros españoles como Morales, con quien Arias se encontraba en pleito desde 1778 (AGN, Tribunales, Legajo 45, Expte. 3, Sala 9 35.7.6, fs. 33r.) (Figura 5).

En lo que respecta a la ubicación puntual del fuerte de Abreu, los resultados de la georreferenciación comprueban parcialmente la propuesta de Atilio Cornejo (1934), para quien esta fundación estaría en la finca Peñaflor ubicada a casi $4 \mathrm{~km}$ al noroeste del pueblo de Chicoana y a $2 \mathrm{~km}$ del inicio de la cuesta de la quebrada de Escoipe.

En este lugar el reconocimiento superficial de la evidencia arqueológica se dificulta por las huellas de la agricultura intensiva y el cambio en la fisonomía del paisaje producido por el uso de la maquinaria agrícola. En los pocos lugares donde la agricultura no ha tenido influencia el ambiente propio de una selva de montaña dificulta la identificación de restos.

La escasa descripción que nos queda de la traza de esta fundación nos habla de su ubicación contra la barranca del río, estando "palpables" sus restos, fosa, plaza de armas y "demás señas" (AGN Tribunales Legajo 45 Expte. 20 Sala 9-35.7.6, fs.

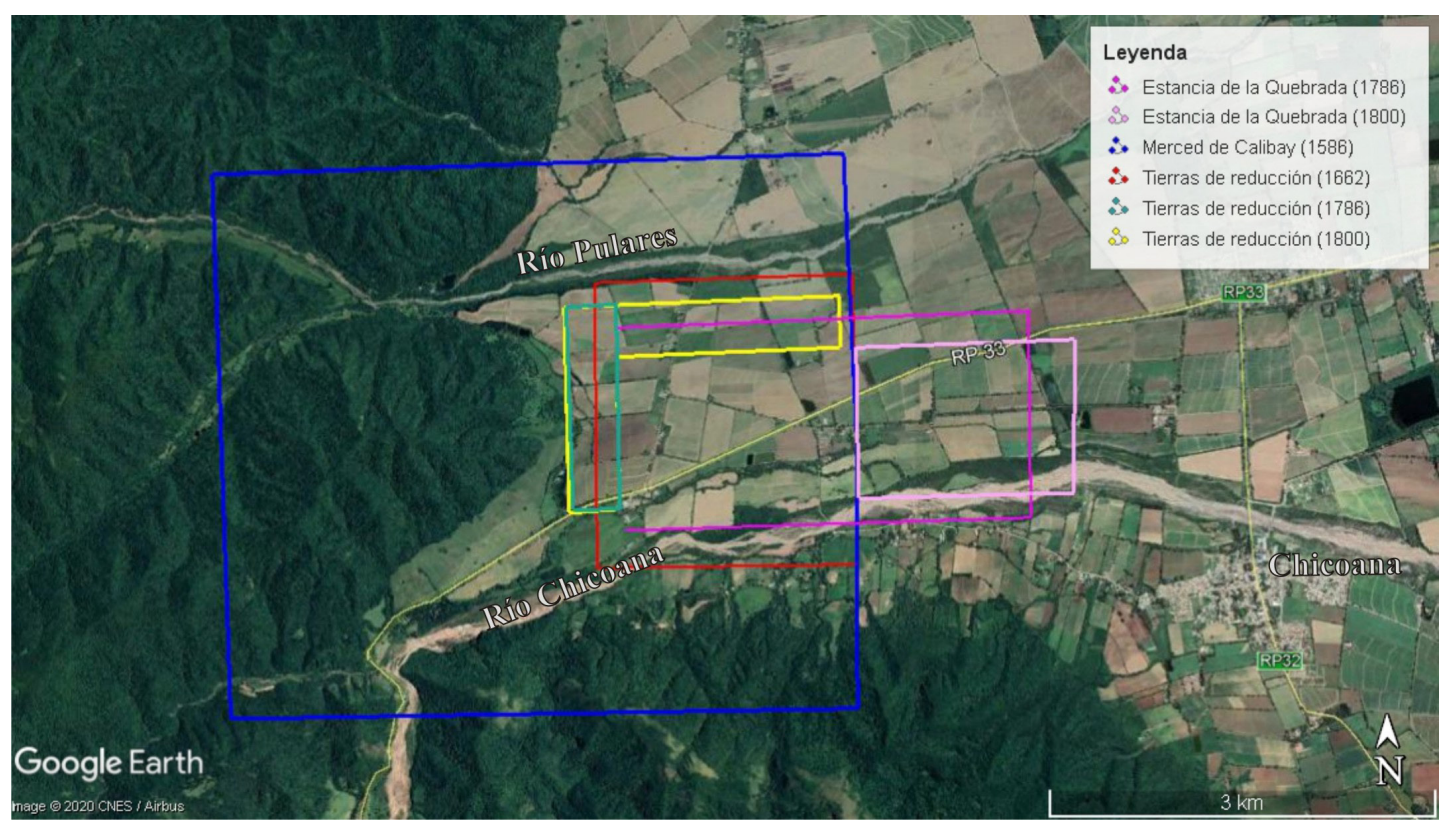

Figura 5. Reconstrucción espacial de la reducción de indios pulares y de la Estancia de la Quebrada de la Compañía de Jesús. 
85 r.). Es por ello que realizamos en las márgenes del río Chicoana un sondeo de $1 \mathrm{~m}$ por $1 \mathrm{~m}$ y de $0,40 \mathrm{~m}$ de profundidad que no reveló evidencia arqueológica pero sí mostró el avance de los periódicos aludes que asolan la zona.

El sondeo fue realizado sobre una gruesa y compacta capa de limo que, según pobladores locales, llega a una potencia de $3 \mathrm{~m}$ en algunos lugares. Esto sugiere que cualquier fundación por imponente que fuese debe haber desaparecido bajo los episodios periódicos de este fenómeno (uno de estos destruyó por completo el pueblo de San Fernando de Escoipe en 1973).

La única ubicación que podría haber preservado de estos sucesivos aludes (que probablemente se sucedieran en la época tal como ahora) a la protociudad con esa magnitud es en donde se encuentra Peñaflor tal como Atilio Cornejo afirmara, al estar a $10 \mathrm{~m}$ por arriba del lecho del río y al pie de una barranca de abrupta pendiente, la que podría haber tenido su utilidad táctica en la defensa contra los ataques indígenas. La ubicación definitiva, no obstante, aún está abierta a nuevas pesquisas que presentan como limitantes el cambio radical en la fisonomía del paisaje debido a la explotación agrícola intensiva que en esa zona se produce en forma de plantaciones de tabaco.

\section{Palabras finales}

El análisis de fuentes históricas, la georreferenciación de los mapas surgidos de los litigios por este despojo y la reconstrucción del paisaje colonial nos muestran que la génesis y desarrollo de la dominación europea en el valle de Lerma, como resultado de una desposesión progresiva de tierras indígenas, sigue una lógica distinta a la estudiada por Quiroga (2010) para el caso de Malfín, en donde el hábitat natural "de quebradas y huaycos", además de ser el ámbito de la reproducción social de los grupos indígenas, favorecía la resistencia al poder colonial.

En sentido inverso, a los pulares del siglo XVI se los traslada desde "la cordillera, lomas y vertiente" en donde "están a donde no hay entera comodidad de tierras ni espacio para ellas adonde poder sembrar ni regar" (su hábitat natural) a "las faldas guaycos y arroyos" de la boca de la quebrada de Escoipe a $20 \mathrm{~km}$ al noreste de su asiento original, alegando que este traslado es en realidad una restitución de sus tierras (Giudicelli 2013).

Mientras que el hábitat natural de los calchaquíes se centraba en las laderas y valles altos transversales a los grandes cursos de agua para la explotación agrícola y pastoril, la ocupación española se dio principalmente en el fondo de valle siguiendo el curso de los ríos (Rodríguez 2017), por lo que trocar la seguridad de los cerros por un medio más favorable al asiento español parece una práctica impuesta para poner al alcance de las nacientes estancias a una mano de obra peligrosamente cercana al valle Calchaquí.

Estos procesos de desnaturalización fueron seguidos de numerosos mecanismos de desposesión más solapados que se observan también en otros sectores de la gobernación del Tucumán como Santa María, entre los que se cuentan los traslados para saca de ganado, el servicio personal en estancias alejadas, la partición de las encomiendas y el despojo de sus tierras (Rodríguez 2008).

La metodología elegida fue de utilidad para dar cuenta de este mecanismo de dominación, además de permitir la ubicación de las tierras del despojo y de la magnitud del mismo a pesar de carecer aún de confirmación arqueológica.

Se plantea para el futuro indagar acerca de los procesos prehispánicos del área de los "llanos de Salta" y de la quebrada de Escoipe para compararlos entre sí y con el sustrato arqueológico de los valles de Lerma y Calchaquí en perspectiva comparativa, por un lado, y por otro, informarnos acerca de los procesos posteriores a la independencia, para tener una mirada de larga duración y acceder así al panorama completo de las rupturas y continuidades entre dos procesos de dominación colonial, el incaico y el europeo.

\section{Agradecimientos}

Al CONICET, a mis directoras María Ester Albeck y Sara Mata, a la familia Borelli, López y Frías, por los valiosos datos de las fincas estudiadas, al Museo de Antropología de Salta, a su director, Lic. Leonardo Mercado y colaboradores por los permisos de excavación. A Claudia Macoritto y Fernanda López por la lectura del manuscrito y por sus valiosas sugerencias. 


\section{Referencias Citadas}

Bodenhamer, D. J., J. Corrigan y T. M. Harris (eds.) 2010 The Spatial Humanities: GIS and the Future of Humanities Scholarship. Indiana University Press, Indiana.

Buisseret, D.

2007 "Spanish Colonial Cartography". En The History Of Cartography. Cartography In The European Renaissance, editado por David Woodward. University of Chicago Press, Chicago.

Castro Olañeta, I.

2007 Indios encomendados, indios registrados, indios omitidos por el Visitador Luján de Vargas. Gobernación del Tucumán, siglo XVII. XI Jornadas Interescuelas/Departamentos de Historia, pp. 1-25. Departamento de Historia, Facultad de Filosofía y Letras, Universidad de Tucumán, San Miguel de Tucumán.

Castro Olañeta, I.

2018 Las encomiendas de Salta (Gobernación del Tucumán, siglo XVII). Andes 29 (2). Instituto de Investigaciones en Ciencias Sociales y Humanidades, Salta.

Cornejo, A.

1934 Apuntes Históricos sobre Salta. Editorial Ferrari Hermanos, Buenos Aires.

Dávila, F. J. y E. Camacho

2012 "Georreferenciación de documentos cartográficos para la gestión de archivos y cartotecas. Propuesta Metodológica". Revista Catalana de Geografía XVII (46): 1-9.

Delano Smith, C.

2007 "Signs on printed topographical maps c. 1470 to c. 1649”. En History Of Cartography Vol. 3, editado por David Woodward, University of Chicago Press, Chicago.

Giudicelli, C.

2011 "La raya de los Pulares. Institution d'une frontière indienne coloniale au sein du Valle Calchaquí (1582-1630)". En Les Indiens des frontières coloniales, dirigido por Luc Capdevila, Jimena Obregón Iturra y Nicolás Richard, pp. 27-57, PUR, Rennes.

Giudicelli, C.

2013 "Calibay o la tempestad. Debate en torno a un documento "indígena" de la Salta primitiva". Corpus Archivos Virtuales de la Alteridad Americana 3 (1).

Giudicelli, C.

2018 "Disciplinar el espacio, territorializar la obediencia. Las políticas de reducción y desnaturalización de los diaguita-calchaquíes (siglo XVII)". Chungara. Revista de Antropología Chilena 50 (1): 133-144.

González Rodríguez, A.

1982 "Notas sobre el traslado de indígenas en la jurisdicción de Salta". Temas Americanistas 1: 49-62.

Harley, J. B.

1989 "Deconstructing the Map". Cartographica 26 (2): 1-20.

Knowles, A. K.

2005 "Emerging Trends in Historical GIS". Historical Geography 33: 7-13.

Larrouy, A.

1927 Documentos del Archivo de Indias para la historia del Tucumán (I). Rosso y Cía. impresores, Buenos Aires.

Levillier, R.

1920 Gobernación del Tucumán: Papeles de Gobernadores en el siglo XVI. Documentos del Archivo de Indias T. 1. Imprenta de Juan Pueyo, Madrid.
Lorandi, A. M.

1988 "La resistencia y rebeliones de los diaguito-calchaquí en los siglos XVI y XVII". Revista de Antropología III (6): 3-17.

Lorandi, A. M.

2005 The Spanish King of the Incas. The Epic Life of Pedro Bohorques. University of Pittsburgh Press.

Mata, $\mathrm{S}$.

2005 Tierra y poder en Salta: el Noroeste Argentino en Vísperas de la Independencia. CEPIHA, Salta.

Mignone, $\mathrm{P}$.

2020 "Empleo del modelado predictivo de Sistemas de Información Geográfica para el hallazgo de caminos con componentes inkaicos entre el valle de Lerma y la quebrada de Escoipe, Salta-Argentina". Anales de Arqueología y Etnología 74 (2): 107-126.

Piossek Prebisch, T.

1983 Pedro Bohorquez. El Inca del Tucumán, 1656-1659, Tucumán, Edición del Autor.

Quintián, J. I.

2008 "Articulación política y etnogénesis en los valles calchaquíes. Los pulares durante los siglos XVII y XVIII". Andes 19: 299-325.

Quiroga, L.

2010 "En sus huaycos y Quebradas: formas Materiales de la Resistencia en las tierras de Malfín". Memoria Americana 18 (2): 185-209.

Quiroga, L.

2017 "Entramados rebeldes de puna y valles en el Tucumán (siglo XVII). Valle de Londres, provincia de los diaguitas. Una perspectiva cartográfica". Estudios Atacameños Arqueología y Antropología Surandinas 55: 203-218.

Quiroga, L., M. N. Hopkins Cardozo y A. E. Alvarado

2018 "Los pulares: entre la guerra y la encomienda en las tierras altas del Tucumán colonial, virreinato del Perú (1577-1630)". Andes 29 (2).

Rodríguez, L. B.

2008 Después de las Desnaturalizaciones. Transformaciones Socio-Económicas y Étnicas al sur del Valle Calchaquí. Santa María, Fines Siglo XVII-Fines del XVIII. Antropofagia, Buenos Aires.

Rodríguez. L. B.

2017 "Efectos imprevistos de las desnaturalizaciones del valle Calchaquí (Noroeste argentino). El 'doble asentamiento' como estrategia de resistencia". Chungara, Revista de Antropología Chilena 49 (4): 1-12.

Siebert, L.

2000 "Using GIS to Document, Visualize, and Interpret Tokyo's Spatial History". Social Science History 24 (3): 537-574.

Rumsey, D. y M. Williams

2002 "Historical Maps in GIS. Integrating historical maps in GIS". En Past Time, Past Place: GIS For History, editado por Anne Kelly Knowles, pp. 1-18, ESRI Press, California.

Tell, S.

2018 "Autoridades y conflictos de jurisdicción en "pueblos de indios". Córdoba, Gobernación del Tucumán, 1750-1810". Revista Complutense de Historia de América 44: 163-186.

Vitry, C.

2004 "Camino de los diaguitas y del Inga en Escoipe. Intersecciones entre la Historia y la Arqueología". Revista Escuela de Historia. Año 3, Vol. 1 (3). Edición electrónica: http: //www.unsa.edu.ar/histocat/revista/revista0313. htm (visitada el 11/01/2021). 


\section{Notas}

1 La cartografía base empleada es un DEM(Digital Elevation Model o modelo digital de elevaciones) del satélite ALOS PALSAR (de 12,5 m de resolución espacial) e imágenes satelitales LANDSAT 8 (30 m de resolución espacial, bandas 4 y 5) ambos de acceso libre, que fueron trabajados con la plataforma SIG Quantum GIS versión 2.18.0 Las Palmas de G. C. 